\title{
Comparison of Lead-Free Solder Joints Made by Immersion Gold Plating with Those Produced by Autocatalytic Electroless Gold Plating
}

\author{
Kiyotomo Nakamura ${ }^{1}$, Ikuo Shohji ${ }^{2}$, Hiroki Goto ${ }^{2}$ and Toshikazu Ookubo ${ }^{1}$ \\ ${ }^{1}$ Technical Research Institute, Toppan Printing Co., Ltd., Sugito 345-8508, Japan \\ ${ }^{2}$ Department of Mechanical System Engineering, Gunma University, Kiryu 376-8515, Japan
}

\begin{abstract}
Electroless $\mathrm{Ni} / \mathrm{Au}$ plating is presently in use with high-density Jisso technology in the manufacture of electrical appliances. Electroless $\mathrm{Ni} / \mathrm{Au}$ plating is said to be less satisfactory than conventional electrolytic plating with respect to the quality of solder joints and lead-free solder in particular. The reason for this is considered the P-rich layer which forms at the interface of solder bulk and Ni layer but this has yet to be fully confirmed.

Solder joints made by electroless $\mathrm{Ni} / \mathrm{Au}$ plating and $\mathrm{Sn}-3$ mass $\% \mathrm{Ag}-0.5$ mass $\% \mathrm{Cu}$ lead-free solder balls were examined here for reliability assessment under high temperature storage, using an electroless $\mathrm{Ni} / \mathrm{Au}$ layer made by autocatalytical deposition and another made by immersion Au plating. Interfacial structure and solder pull strength data for the two layers were compared as basis for this assessment and confirm if solder joints made by electrolytic plating is actually superior.

At the interface of both layers, cavity formation was found to have occurred by Ni corrosion during Au plating and the number of which appeared to be a factor determining solder joint reliability. Electrolytic Au plating not accompanied by Ni corrosion should provide solder joints with reliability exceeding that by electroless Au plating.
\end{abstract}

(Received June 21, 2005; Accepted October 14, 2005; Published December 15, 2005)

Keywords: lead-free solder, Sn-3 mass\%Ag-0.5 mass\%Cu, electroless plating, immersion method, autocatalytic method, ball shear strength, ball pull strength, cavities

\section{Introduction}

Owing to the toxicity of lead, with its potential risk to human health, the use of lead-free soldering is being given serious consideration in the manufacture of electronic devices and appliances. ${ }^{1)}$ Because of lead-free solder with poor wettability on a copper electrode, the copper electrode surface must thus be finished with electroless $\mathrm{Ni} / \mathrm{Au}$ plating to ensure adequate wettability of the solder in the electronic manufacture industry. In $\mathrm{Ni} / \mathrm{Au}$ plating, with the advance of high-density Jisso technology, ${ }^{2)}$ electroless plating is finding greater application since there is no requirement for feeding leads during plating. In this issue, Jisso technology means mounting, bonding, packaging, etc. The reliability of solder joints, especially lead-free solder joints, in electroless plating is said to be less satisfactory compared to electrolytic plating. ${ }^{3,4)}$ This problem may possibly derive from the P-rich layer formed between solder bulk and the $\mathrm{Ni}$ layer in electroless plating ${ }^{5-7)}$ though this has yet to be fully confirmed. A method has been established to lessen $\mathrm{Ni}$ corrosion as much as possible, using a different electroless $\mathrm{Ni} / \mathrm{Au}$ solution, in which substitution and reducing reactions take place simultaneously. ${ }^{8,9)}$

In this study, evaluation is made of $\mathrm{Sn}-3$ mass $\% \mathrm{Ag}-$ 0.5 mass $\% \mathrm{Cu}$ lead-free solder joints under high temperature storage using electroless Au plating. Results obtained with autocatalytic electroless Au plating involving substitution and reducing reactions are compared with those by immersion Au plating. Immersion Au plating means the Au layer is formed by only the substitution reaction. Examination is made as to why, in electroless plating, solder joints may be less satisfactory than in electrolytic plating.

\section{Experimental Procedure}

A glass-epoxy resin substrate with $0.3 \mathrm{~mm}$ diameter $\mathrm{Cu}$ pads was prepared. On the surface of each pad, electroless $\mathrm{Ni}$ plating was conducted. Ni plating layer thickness was $0.003 \mathrm{~mm}$ and the layer contained 8 mass $\% \mathrm{P}$. The $\mathrm{Cu}$ pads were produced by depositing $\mathrm{Au}$ on the $\mathrm{Ni}$ layer. Au layer thickness in all cases was 90 or $150 \mathrm{~nm}$ at plating times of 10 and $30 \mathrm{~min}$, respectively. For Au plating, a solution was prepared so that $\mathrm{Au}$ deposition would take place by substitution and reducing reactions that occur simultaneously. The Ni/Au layer surface was observed with a scanning electron microscope (SEM). The Au layer was removed with removal solution including $\mathrm{KCN}$. This removal solution is used generally for quality control of $\mathrm{Ni} / \mathrm{Au}$ plating process. And its surface was observed by SEM. A Sn-3 mass\%Ag$0.5 \mathrm{mass} \% \mathrm{Cu}$ lead-free solder ball $0.35 \mathrm{~mm}$ in diameter was prepared as a solder joint by reflow soldering in a reflow furnace. Peak temperature and holding time over $220^{\circ} \mathrm{C}$ in the reflow process were $250^{\circ} \mathrm{C}$ and $60 \mathrm{~s}$, respectively. All solder joints were subsequently exposed to heat treatment at $150^{\circ} \mathrm{C}$ for $500 \mathrm{~h}$. The ball pull test by cold bump pull (CBP) method was carried out prior to and after heat exposure [refer to Fig. 1, Table 1], at a test speed of $10 \mathrm{~mm} / \mathrm{min}$. In this method, vertical force is applied to the solder ball by special jaw and no melting of the solder ball is involved. Following this test, fracture surfaces were examined using an electron probe X-ray microanalyzer (EPMA) and SEM. Additional ball shear tests were conducted, each at a test speed of $15 \mathrm{~mm} / \mathrm{min}$. Microstructural observation of cross sections of solder joints and fracture surfaces after the ball shear test was made by SEM. The results obtained with an Au layer formed by substitution reaction were compared with these obtained for the layer produced by the above current reaction. 

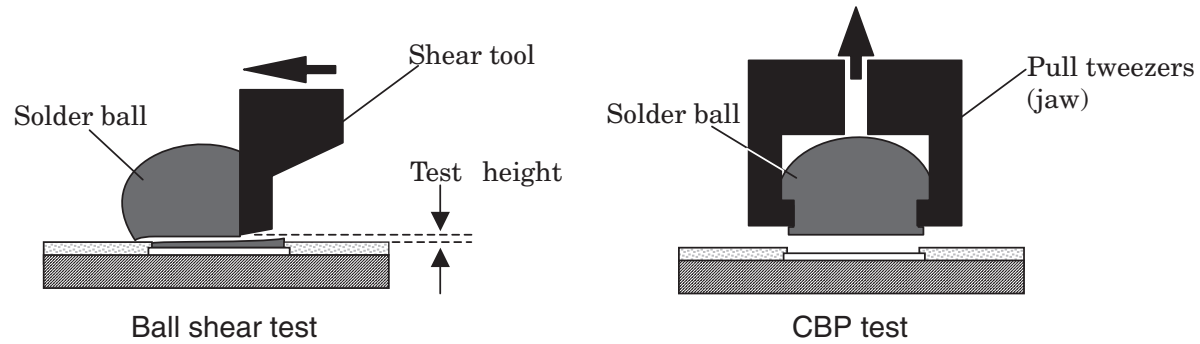

Fig. 1 Schematic section of ball shear and CBP testing.

Table 1 Ball shear and CBP tests conditions.

\begin{tabular}{ccc}
\hline & Shear test & CBP test \\
\hline Measuring equipment & Dage bondtester series & 4000 \\
\hline Testing cartridge & BS5KG & TP5KG \\
\hline Test height & $0.02 \mathrm{~mm}$ & - \\
\hline Test speed & $15 \mathrm{~mm} / \mathrm{min}$ & $10 \mathrm{~mm} / \mathrm{min}$ \\
\hline
\end{tabular}

\section{Results and Discussion}

\subsection{Plating layer surface}

Figure 2 shows the surface of each electroless $\mathrm{Ni} / \mathrm{Au}$ plating layer; that of the Ni layer, following removal of the $\mathrm{Au}$ layer, is presented in Fig. 3. All Ni/Au layer surfaces appeared smooth and were unaffected by Au plating time. Figure 3 shows cavities sub-micron in size and micro cracks to be present on the Ni layer surface at a plating time of 30 min. Cavity formation occurred regardless of the plating solution used. In the current reaction at $30 \mathrm{~min}$, this formation was considerably limited and the $\mathrm{Ni}$ layer surface was without any micro cracks.
Au deposition by substitution reaction requires ionization of $\mathrm{Ni}$ following electron transfer between $\mathrm{Ni}$ and $\mathrm{Au}$. The sites of Ni corrosion are not always the same as those for $\mathrm{Au}$ deposition and are not completely covered by Au. Consequently, these sites may become cavities or micro cracks. ${ }^{10,11)}$ The reagent for the reducing reaction provides electrons to Au ions and according by, Au deposition occurs without $\mathrm{Ni}$ ionization. $\mathrm{Ni}$ corrosion increases with $\mathrm{Ni}$ ionization. The number of cavities on the Ni layer in the current reaction must be less than in the substitution reaction so as to ensure the same Au plating thickness for a specified plating time. In the current reaction, the substitution reaction may contribute little to deposition and the extent of the contribution may be assessed based on the degree of $\mathrm{Au}$ deposition and corresponding $\mathrm{Ni}$ elution into the plating solution. This contribution in the present study was considered to be approximately $20 \%$ based on data from a previous study. In the current reaction, cavity formation may thus be considered quite limited.

\subsection{Ball pull strength}

Figure 4 shows the results of ball pull tests. Ball pull strength after soldering was essentially the same in all cases
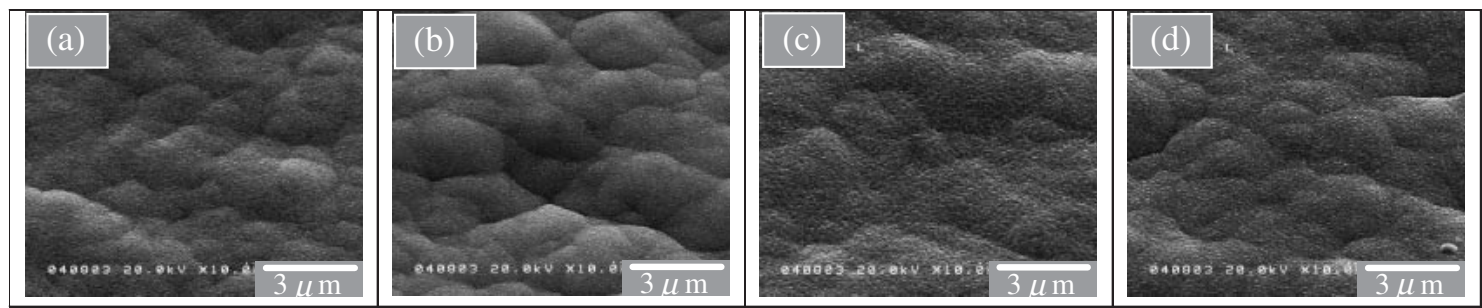

Fig. 2 SEM images of electroless Ni/Au plating layer surfaces. (a) Substitution and reducing reactions at 10 min, after Au plating. (b) Substitution reaction at $10 \mathrm{~min}$, after Au plating. (c) Substitution and reducing reactions at $30 \mathrm{~min}$, after Au plating. (d) Substitution reaction at $30 \mathrm{~min}$, after Au plating.
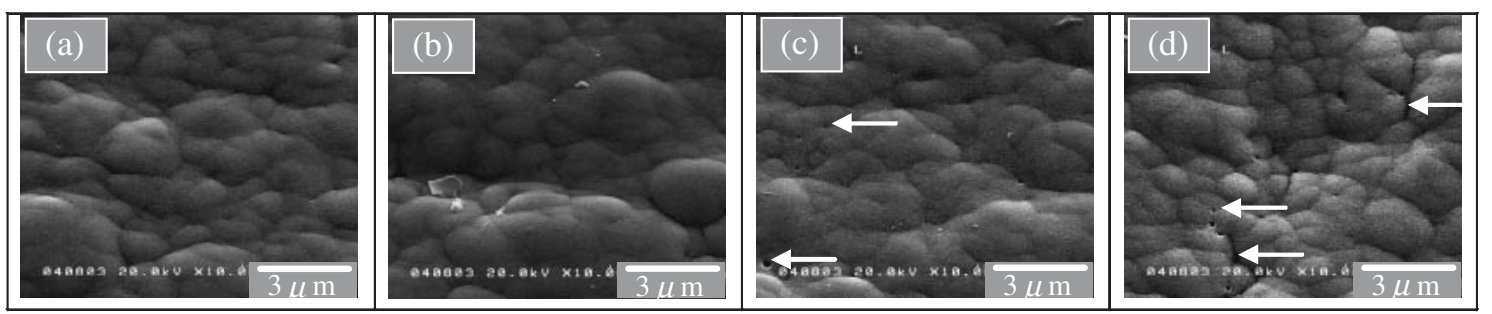

Fig. 3 SEM images of electroless Ni plating layer surfaces subsequent to removal of the Au layer. (a) Substitution and reducing reactions at $10 \mathrm{~min}$. (b) Substitution reaction at $10 \mathrm{~min}$. (c) Substitution and reducing reactions at $30 \mathrm{~min}$. (d) Substitution reaction at 30 min. Cavities and Micro cracks are denoted by $(\leftarrow)$. 


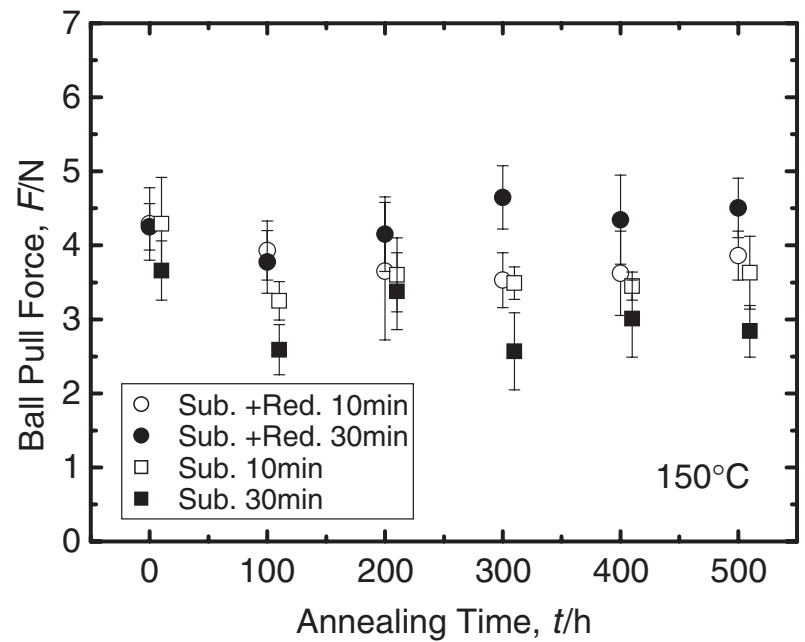

Fig. 4 Transition of ball pull strength with course of annealing at $150^{\circ} \mathrm{C}$.

but in the substitution reaction at $30 \mathrm{~min}$, this parameter was reduced by approximately $25 \%$ following $100 \mathrm{~h}$ annealing. With any additional annealing, no further decrease occurred. For plating time of $10 \mathrm{~min}$, pull strength for the substitution reaction was less than that for substitution and reducing reactions conducted simultaneously, after $100 \mathrm{~h}$ annealing as well as plating time of $30 \mathrm{~min}$. Figures 5 and 6 show SEM images of fracture surfaces subsequent to ball pull tests. For each image, at 30 min of substitution reaction when ball pull strength was relatively less, solder residuals appeared on all fracture surfaces on completion of the test, accompanied by numerous dimples, as can be seen from Figs. 5(d) and 6(d). Figure 7 shows cross section of solder joint prior to ball pull test after reflow soldering. Before the ball pull test, no voids, which may cause dimples, had appeared. The dimples may possibly have been due to ballooning of micro void-like structures in the vicinity of solder joints. Ballooning may possibly arise from greater pull stress in the ball pull test. ${ }^{12)}$ EPMA quantitative data for each area, marked with alphabetical letters in Figs. 5(a), (c) and 6(a), (c), are presented in Table 2. Shohji et al. ${ }^{13)}$ presumed $\mathrm{Ni}-\mathrm{Sn}-\mathrm{P},(\mathrm{Cu}, \mathrm{Ni})_{6} \mathrm{Sn}_{5}$ and a P-rich layer to be formed during the substitution reaction and in this study, the same compound layers were presumed in the current reaction.

Based on the above, fracture formation may be concluded to occur at the interface between certain compound layers when ball pull strength is essentially constant. Reduction in ball pull strength may possibly result from and be limited to the particular site of dimple formation.

\subsection{Ball shear strength}

Ball shear test results are given in Fig. 8. During heat treatment of solder joints on glass-epoxy resin, ball shear strength was noted to decrease slightly and in the current reaction, was virtually unaffected by plating time. Ball shear strength in current reaction and substitution reaction were basically the same as at $10 \mathrm{~min}$ but at $30 \mathrm{~min}$, strength for the latter reaction was $15 \%$ less, possibly owing to the particular mode of fracture in the ball shear test. Figure 9, which corresponds to the situation following soldering and Fig. 10, to that after annealing at $150^{\circ} \mathrm{C}$ for $500 \mathrm{~h}$, show fracture surfaces on completion of the ball shear test. At $10 \mathrm{~min}$ of current reaction and $30 \mathrm{~min}$ of substitution reaction at the same shear strength, dimples had almost entirely disappeared from fracture surfaces, as evident from Figs. 9(a)-(c) and Fig. 10(a)-(c). Cross sections of solder joints observed by SEM are shown in Figs. 11 and 12. Figures 11(a)-(c) and 12(a)-(c) indicate ductile breaking in cross sections. Solder breaking is thus shown to occur at the solder bulk part of
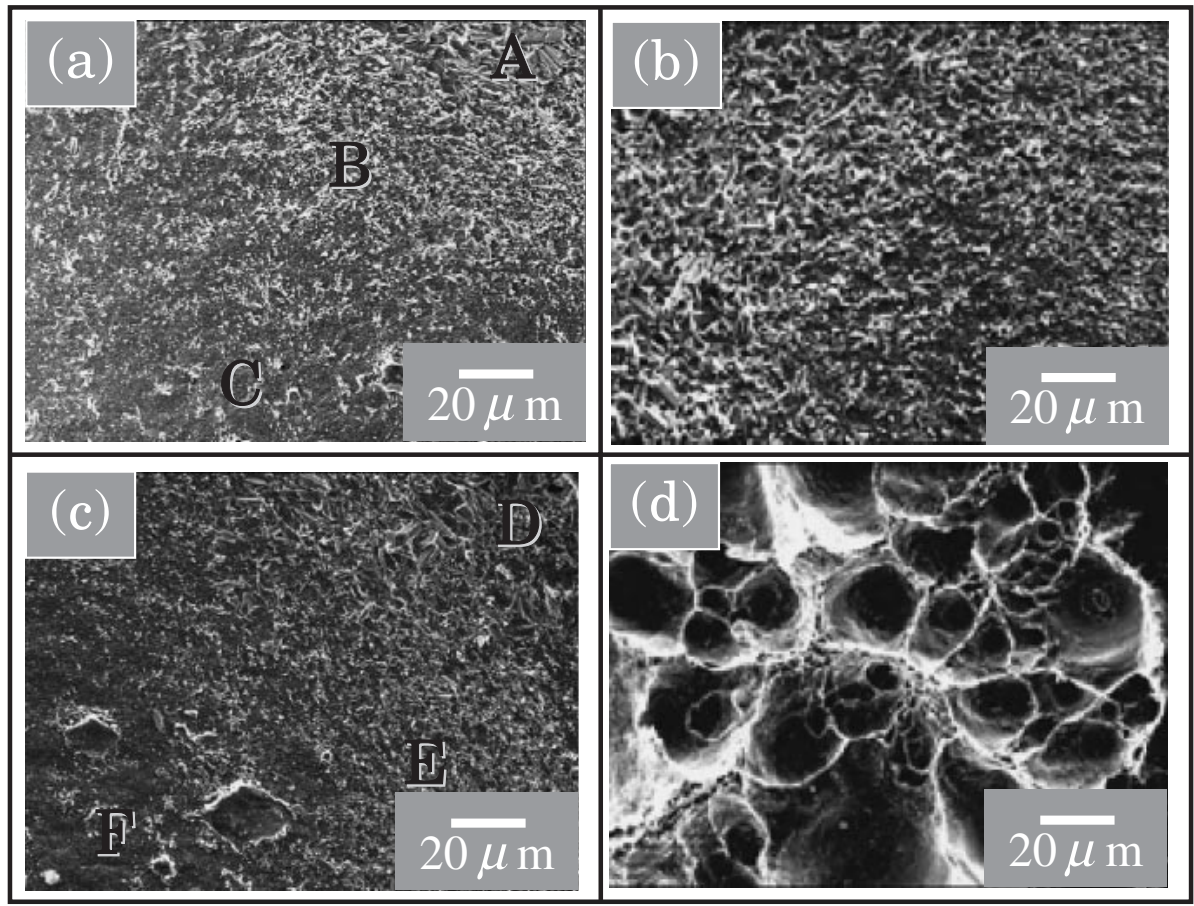

Fig. 5 SEM images of fracture surfaces after ball pull test (soldering). (a) Substitution and reducing reactions at 10 min. (b) Substitution reaction at $10 \mathrm{~min}$. (c) Substitution and reducing reactions at $30 \mathrm{~min}$. (d) Substitution reaction at $30 \mathrm{~min}$. 

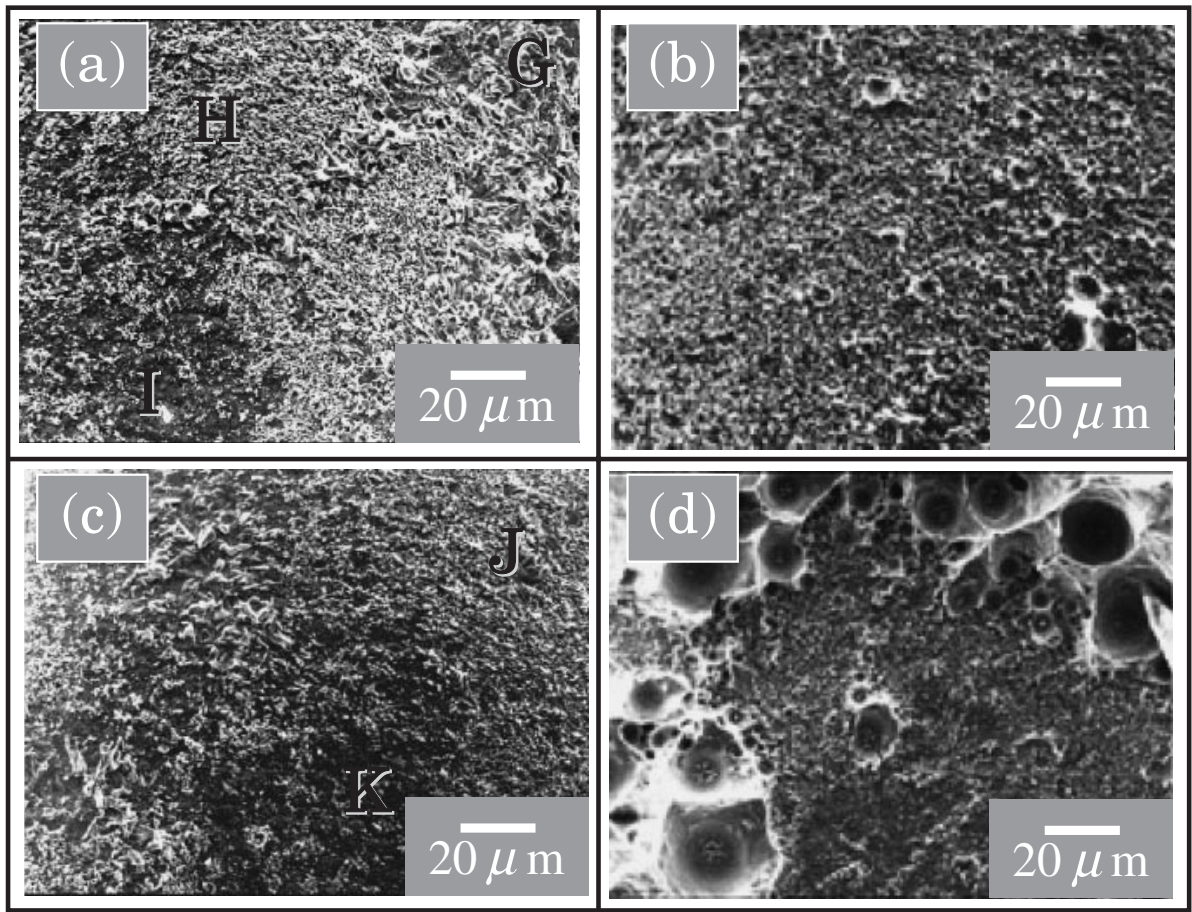

Fig. 6 SEM images of fracture surfaces after ball pull test (annealing at $150^{\circ} \mathrm{C}$ for $500 \mathrm{~h}$ ). (a) Substitution and reducing reactions at $10 \mathrm{~min}$. (b) Substitution reaction at $10 \mathrm{~min}$. (c) Substitution and reducing reactions at $30 \mathrm{~min}$. (d) Substitution reaction at $30 \mathrm{~min}$.

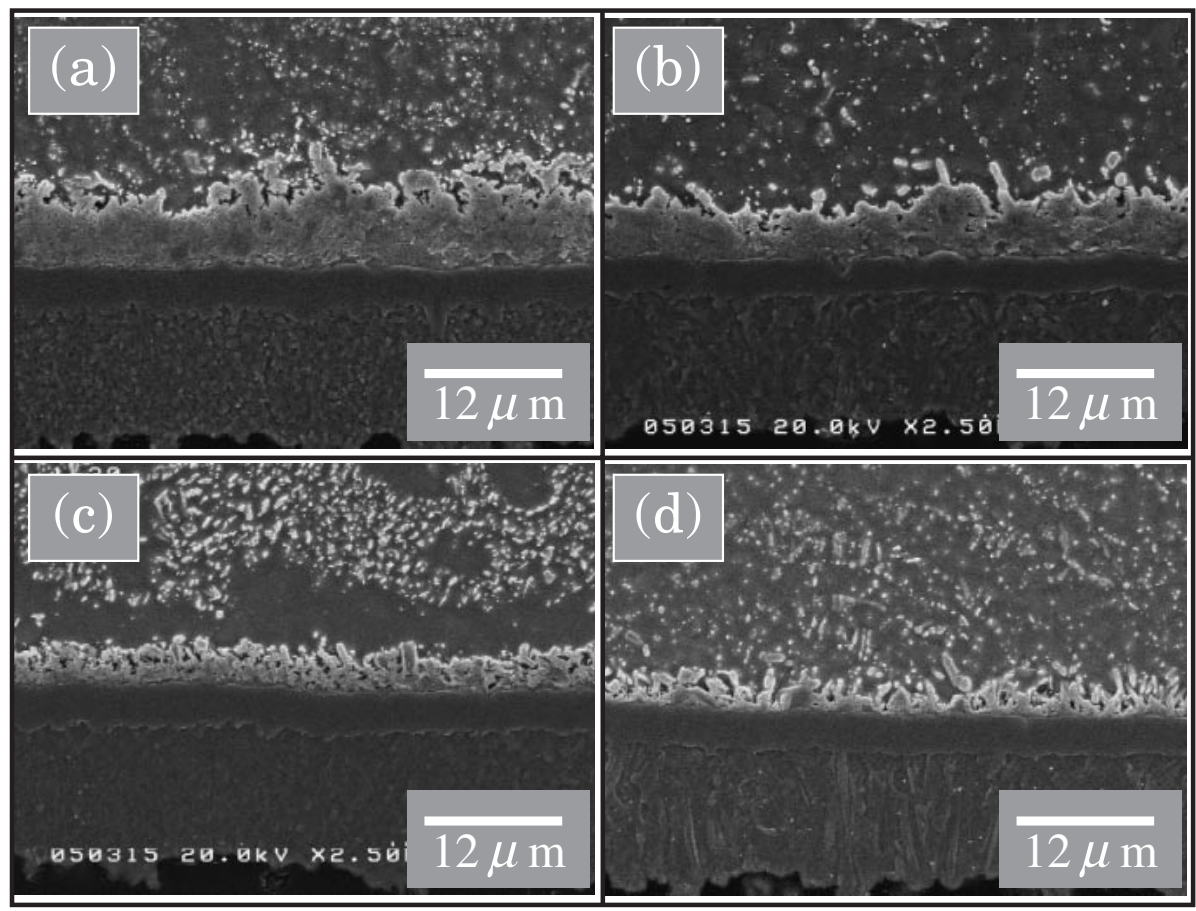

Fig. 7 SEM images of cross sections of solder joint prior to ball pull test (soldering). (a) Substitution and reducing reactions at $10 \mathrm{~min}$. (b) Substitution reaction at $10 \mathrm{~min}$. (c) Substitution and reducing reactions at $30 \mathrm{~min}$. (d) Substitution reaction at $30 \mathrm{~min}$.

current reaction at 10 , and $30 \mathrm{~min}$ and the substitution reaction at $10 \mathrm{~min}$. Accordingly, solder bulk strength is the same in these cases. At 30 min of substitution reaction, ball shear strength was less and numerous dimples had appeared on the fracture surface on completion of the ball shear test [refer to Figs. 9(d), 10(d)]. Dimples were present at the interface between the Ni layer and bulk solder, as can be seen from the cross sections of Figs. 11(d) and 12(d) and their formation may have given rise to reduction in ball shear strength. There is a possibility that reduction in ball shear strength by dimple formation may serve to lessen stress and improve the reliability of solder joint in certain cases, but generally reduction will result in insufficient reliability. Figure 13 shows magnified cross sections of fracture surfaces 
Table 2 EPMA quantitative analysis results for each area marked with alphabetical letters in Figs. 5(a), (c) and 6(a), (c).

\begin{tabular}{|c|c|c|c|c|c|c|c|c|}
\hline $\begin{array}{l}\text { Sample } \\
\text { name }\end{array}$ & $\begin{array}{l}\text { Analysis } \\
\text { area }\end{array}$ & $\mathrm{Sn}$ & $\mathrm{Ag}$ & $\mathrm{Cu}$ & $\mathrm{Ni}$ & $\mathrm{P}$ & $\mathrm{Au}$ & $\begin{array}{l}\text { Inferential } \\
\text { phase }\end{array}$ \\
\hline \multirow{2}{*}{$\begin{array}{l}\text { Initial } \\
10 \mathrm{~min}\end{array}$} & A & 45.9 & 0.4 & 36.5 & 16.9 & 0.2 & 0.1 & $(\mathrm{Cu}, \mathrm{Ni})_{6} \mathrm{Sn}_{5}$ \\
\hline & $\mathrm{C}$ & 3.3 & 0.0 & 1.3 & 71.0 & 24.4 & 0.0 & P-rich phase \\
\hline \multirow{2}{*}{$\begin{array}{l}\text { Initial } \\
30 \mathrm{~min}\end{array}$} & $\mathrm{D}$ & 41.2 & 0.2 & 35.2 & 21.5 & 0.0 & 1.8 & $(\mathrm{Cu}, \mathrm{Ni})_{6} \mathrm{Sn}_{5}$ \\
\hline & $\mathrm{F}$ & 3.4 & 0.0 & 1.9 & 66.5 & 28.3 & 0.0 & P-rich phase \\
\hline \multirow{3}{*}{$\begin{array}{c}150^{\circ} \mathrm{C} 500 \mathrm{~h} \\
30 \mathrm{~min}\end{array}$} & G & 38.1 & 0.0 & 37.4 & 22.1 & 2.1 & 0.3 & $(\mathrm{Cu}, \mathrm{Ni})_{6} \mathrm{Sn}_{5}$ \\
\hline & $\mathrm{H}$ & 20.6 & 0.0 & 30.1 & 36.8 & 12.1 & 0.4 & $\mathrm{Sn}-\mathrm{Ni}-\mathrm{P}$ \\
\hline & $\mathrm{I}$ & 3.6 & 0.0 & 6.6 & 60.2 & 29.2 & 0.4 & P-rich phase \\
\hline $\begin{array}{c}150^{\circ} \mathrm{C} 500 \mathrm{~h} \\
30 \mathrm{~min}\end{array}$ & $\mathrm{~J}$ & 24.3 & 0.1 & 25.1 & 38.7 & 10.7 & 1.1 & $\mathrm{Sn}-\mathrm{Ni}-\mathrm{P}$ \\
\hline
\end{tabular}

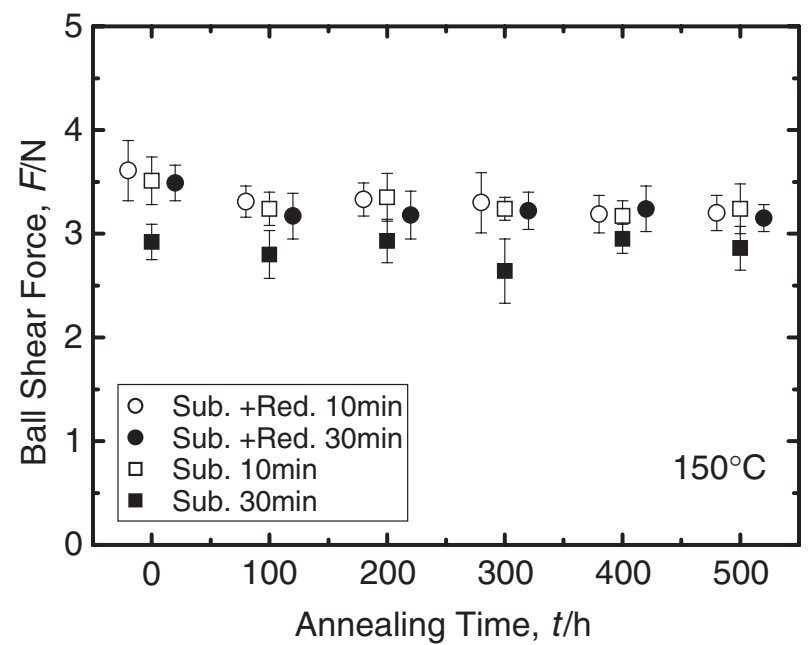

Fig. 8 Transition of ball shear strength with course of annealing at $150^{\circ} \mathrm{C}$. of Fig. 11(d). Micro voids could be seen at the bottom of the dimples following the ball shear test and possibly may be the same as the cavities in Fig. 3(d).

While finishing the copper electrode by electroless $\mathrm{Ni} / \mathrm{Au}$ plating for soldering, cavities may form on a $\mathrm{Ni} / \mathrm{Au}$ layer to give rise to dimples at the time of soldering and these may subsequently cause reduction in shear strength. In electrolytic plating, there should be no Ni corrosion during Au deposition and hence no cavity formation on the Ni layer surface. Thus solder ball joint strength is stably maintained even if solder joints incur shear stress. It should be possible to control cavity formation in electroless plating through use of appropriate plating conditions.

\section{Conclusions}

(1) At 30 min of Au plating, cavity formation occurred following removal of the Au layer for both current and substitution reactions.
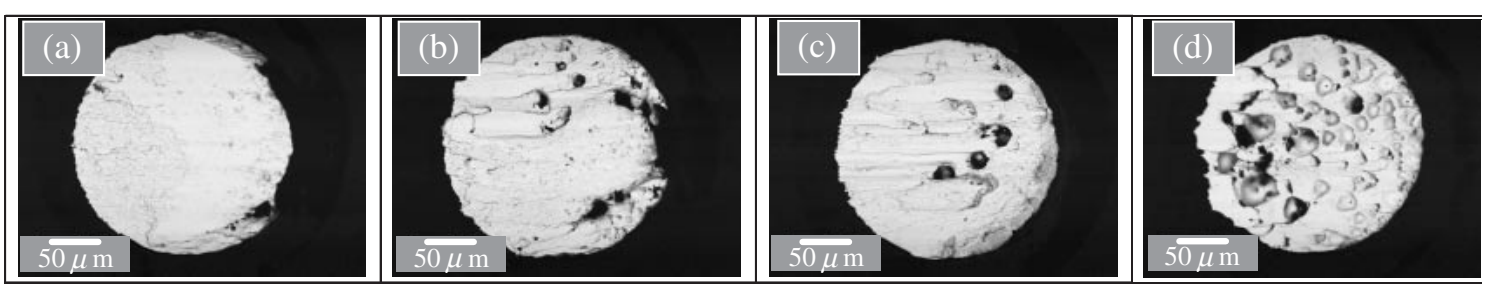

Fig. 9 SEM images of fracture surfaces after ball shear tests (soldering). (a) Substitution and reducing reactions at 10 min. (b) Substitution reaction at $10 \mathrm{~min}$. (c) Substitution and reducing reactions at $30 \mathrm{~min}$. (d) Substitution reaction at $30 \mathrm{~min}$.
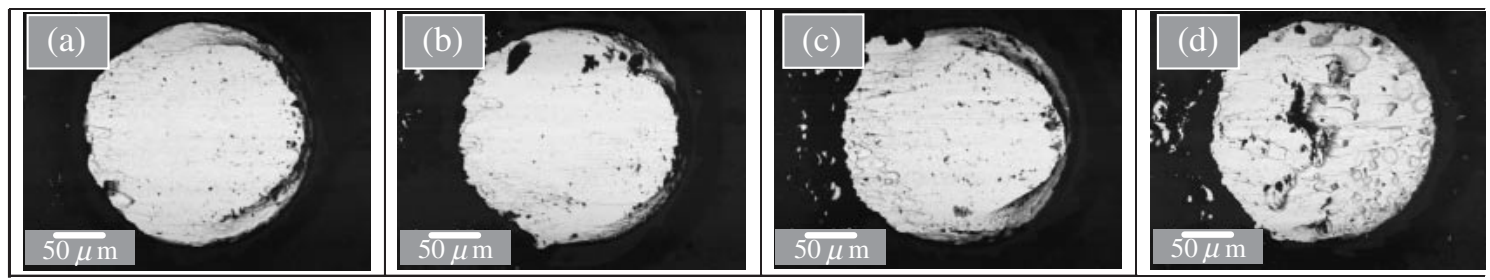

Fig. 10 SEM images of fracture surfaces after ball shear test (annealing at $150^{\circ} \mathrm{C}$ for $500 \mathrm{~h}$ ). (a) Substitution and reducing reactions at $10 \mathrm{~min}$. (b) Substitution reaction at $10 \mathrm{~min}$. (c) Substitution and reducing reactions at $30 \mathrm{~min}$. (d) Substitution reaction at $30 \mathrm{~min}$. 

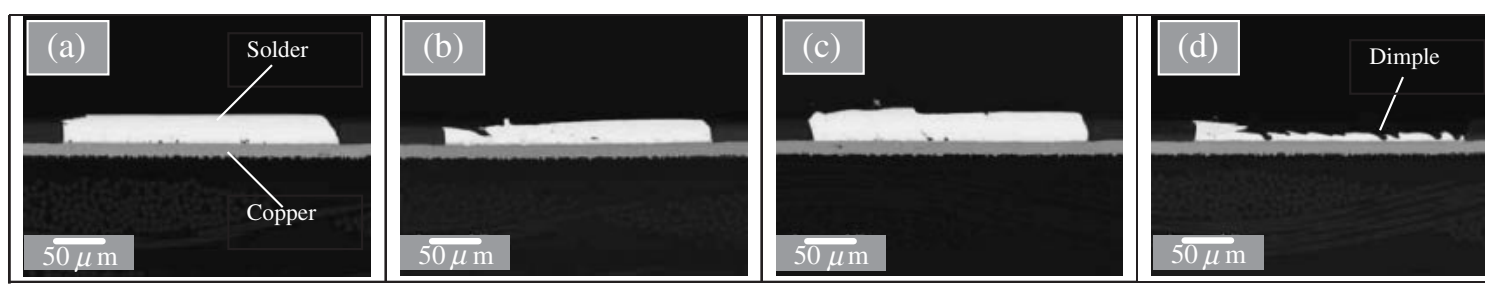

Fig. 11 SEM images of cross sections of fracture surfaces after ball shear test (soldering). (a) Substitution and reducing reactions at $10 \mathrm{~min}$. (b) Substitution reaction at $10 \mathrm{~min}$. (c) Substitution and reducing reactions at $30 \mathrm{~min}$. (d) Substitution reaction at $30 \mathrm{~min}$.
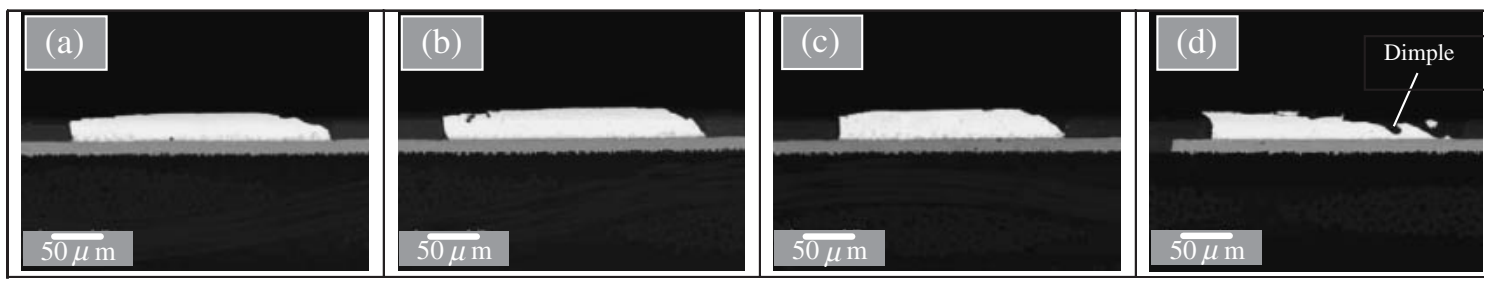

Fig. 12 SEM images of cross sections of fracture surfaces after ball shear test (annealing at $150^{\circ} \mathrm{C}$ for $500 \mathrm{~h}$ ). (a) Substitution and reducing reactions at $10 \mathrm{~min}$. (b) Substitution reaction at $10 \mathrm{~min}$. (c) Substitution and reducing reactions at $30 \mathrm{~min}$. (d) Substitution reaction at $30 \mathrm{~min}$.
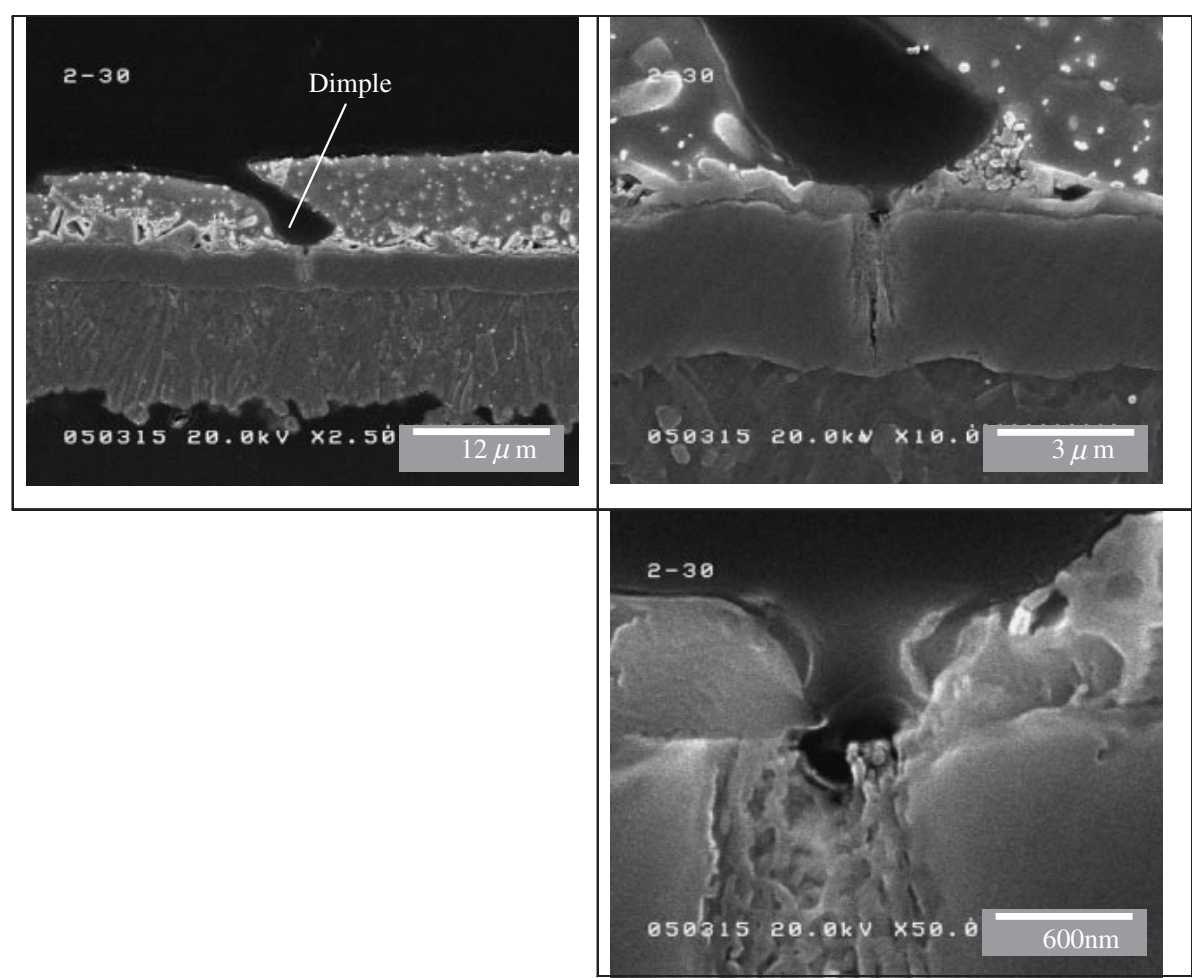

Fig. 13 SEM close-up images of cross sections of fracture surfaces in substitution reaction at 30 min after ball shear test (soldering).

(2) In the ball pull test, at 30 min substitution reaction, ball pull strength was less and solder residuals could be found on fracture surfaces following completion of the ball pull test, along with numerous dimples.

(3) Ball shear strength was noted to level off to a constant value with heat treatment at $150^{\circ} \mathrm{C}$ for $500 \mathrm{~h}$. Shear strength was the same in all cases, thus clearly indicating only solder breakage to occur, though this was not the case with the substitution reaction at $30 \mathrm{~min}$.

(4) At 30 min substitution reaction, dimple formation was noted on the fracture surface with completion of the ball shear test, with consequent reduction in shear strength $15 \%$, this being more than in any other case.

(5) Micro voids at the bottom of the dimples may possibly be indication that fracture of solder joints is initiated by cavities on the Ni layer.

(6) The lesser reliability of solder joints in electroless plating compared to electrolytic plating may possibly arise from cavity formation subsequent to Au plating on the Ni layer surface. 


\section{REFERENCES}

1) K. Nimmo: Proc. JISSO/PROTEC Forum Japan 2001 (Japan Electronics and Information Technology Industries Association, 2001) pp. 111-118.

2) H. Kasuga: Proc. SMT/PROTEC Forum '99 (Electronic Industries Association of Japan, 1999) pp. 75-81.

3) Y. Kariya, K. Nakamura, Y. Tanaka and M. Otsuka: Proc. 6th Symposium on Microjoining and Assembly Technology in Electronics (The Japan Welding Society, 2000) pp. 217-222.

4) H. Otani, K. Honma, Y. Okinaka, T. Osaka, T. Okubo, K. Nakamura and T. Tsukamoto: Collected Abstracts of 17th Annual Meeting of Japan Inst. of Electronics Package (2003) pp. 187-188.

5) K. Shimoyama, Y. Takase, Z. Mitsukoshi and M. Nishiura: Proc. 7th Symposium on Microjoining and Assembly Technology in Electronics (The Japan Welding Society, 2001) pp. 237-240.

6) M. Ito, Y. Tanii, T. Ito, Y. Nakagawa, G. Katagiri, T. Hiramori, A. Hirose and K. F. Kobayashi: Proc. 10th Symposium on Microjoining and Assembly Technology in Electronics (The Japan Welding Society,
2004) pp. 159-164.

7) M. Ito, M. Yoshikawa, Y. Nakagawa, G. Katagiri, T. Hiramori, A. Hirose and K. F. Kobayashi: Proc. 8th Symposium on Microjoining and Assembly Technology in Electronics (The Japan Welding Society, 2002) pp. 231-236.

8) Y. Okinaka and M. Kato: Modern Electroplating, 4th Edition (2000) pp. 705-728.

9) Y. Okinaka and M. Hoshino: Gold Bull. 31 (1998) pp. 3-13.

10) K. Kondo: Shoho kara manabu bishou mekki gijutsu (Kogyo Chosakai Publishing, Japan, 2003) pp. 173-178

11) A. Aiba, K. Kawamura and M. Hasemi: Collected Abstracts of 110th Annual Meeting of Surface Finishing Society of Japan (2004) pp. 6162.

12) N. Hidaka, M. Nagano, M. Shimoda and H. Watanabe: Proc. 11th Symposium on Microjoining and Assembly Technology in Electronics (The Japan Welding Society, 2005) pp. 171-176.

13) I. Shohji, H. Goto, K. Nakamura and T. Ookubo: Proc. 7th International Conference on Ecomaterials (Materials Research Society Singapore, 2005) pp. 309-315. 